\title{
UNIVERSITYOF
}

FORWARD

THINKING

WESTMINSTER用

WestminsterResearch

http://www.westminster.ac.uk/westminsterresearch

Redefining Access: Embracing multimodality, memorability and shared experience in Museums

Eardley, A.F., Mineiro, C., Neves, J. and Ride, P.

This is the peer reviewed version of the following article: Eardley, A., Mineiro, C., Ride, P. and Neves, J. (2016) Redefining Access: Embracing multimodality, memorability and shared experience in Museums Curator, The Museum Journal, Volume 59, Issue 3, July 2016, Pages 263-286, which is published in final form at:

http://dx.doi.org/10.1111/cura.12163

This article may be used for non-commercial purposes in accordance with Wiley Terms and Conditions for Self-Archiving.

The WestminsterResearch online digital archive at the University of Westminster aims to make the research output of the University available to a wider audience. Copyright and Moral Rights remain with the authors and/or copyright owners.

Whilst further distribution of specific materials from within this archive is forbidden, you may freely distribute the URL of WestminsterResearch: ((http://westminsterresearch.wmin.ac.uk/)).

In case of abuse or copyright appearing without permission e-mail repository@westminster.ac.uk 


\section{Redefining Access: \\ Embracing multimodality, memorability and shared experience in Museums}

Dr Alison F. Eardley (corresponding author)

Psychology Department

University of Westminster

115 New Cavendish Street

London W1W 6UW

UK

Tel: +44 (20) 79115000 ext. 69007

E-mail: a.eardley@westminster.ac.uk

Ms Clara Mineiro

Direção Geral do Património Cultural

Palácio Nacional da Ajuda

1349-021 Lisboa

PORTUGAL

Tel: + 351213614290

E-mail: cmineiro@dgpc.pt

Dr Joselia Neves

College of Humanities and Social SciencesHamad bin Khalifa University

Al Luqta Street, Qatar Foundation

Awsaj Building, First Floor

P.O. Box 5825

Qatar

Tel: +974 44546541

E-mail: jneves@qf.org.qa

Dr Peter Ride

Department of English, Linguistics and Cultural Studies

University of Westminster,

32-38 Wells Street

London W1T 3UW

UK

Tel: +44 (0)20 35068982

E-mail:p.e.ride@westminster.ac.uk 


\section{$\underline{\text { Abstract }}$}

Disability access to museums, both physical and intellectual, is generally considered a minority issue. Whilst museums and cultural institutions acknowledge the moral and legal importance of equal access to their establishments, there is generally a conflict between the perceived number of potential visitors that will benefit and the cost implications. Set in the context of research on multisensory learning, this article discusses why disability access is, in fact, a majority issue. It discusses two case studies where an "access for all" museological approach has been applied to access to the collections, with differing success. The article considers how an "access for all" approach would potentially enhance learning, long-term memorability and the 'cultural value' of a museum experience for all visitors. 
Access to cultural sites is a right irrespective of cognitive, sensory or physical ability as covered by Article 27 of the Universal declaration of Human Rights, 1948, and addressed in the EU under the European Disability Strategy 2010-20. It has been increasingly ratified in legal systems internationally, for example: USA, American with Disabilities Act, 1990; UK, Equality Act, 2010. Museums provide sites of learning, social interaction, cultural discourse. They may also play an important role in the enhancement of well-being (Candlin, 2009; Chatterjee \& Noble, 2013). Traditionally, museum and gallery collections have been accessed through sight and strictly without touch (Candlin, 2009; Chatterjee, 2008; Classen, 2005), making them particularly inaccessible for people who are blind.

In line with legislation, many museum and art galleries are trying to provide access to the contents of their collections for blind people via touch tours or verbal description (e.g. Krantz, 2013; Hoyt, 2013). This type of access often relies on pre-booked visits and guided tours. Some institutions have attempted to incorporate open-access tactile and/or auditory facilities within their permanent collections (e.g. V\&A, UK; the Louvre, France; National Museum of Ethnology, Japan; see also Ginley, 2013; Hirose, 2013), although these types of multisensory exhibits tend to be small additions to the main collection, rather than central features. At the same time, recent research has suggested that in Europe alone, the tourism sector is missing out on 142 billion Euros every year due to poor infrastructure, services and attitudes towards travellers with specific access requirements (Economic Impact and Travel Patterns of Accessible Tourism in Europe, 2014).

Despite the moral, legal and financial motivations, the majority of museum collections remain largely inaccessible to visitors with an impairment or disability. Some museums may meet certain physical access requirements for wheelchair users and others may provide touch tours for blind users. However, what the vast majority of institutions have not embraced is an "access for all" ethos, in which a museum can be freely accessed by all visitors, irrespective of their physical, sensory or intellectual abilities (Rappolt-Schlichtmann \& Daley, 2013).

This article will consider "access for all" in light of research findings on multisensory processing in neurologically typical individuals, and case studies of two Portuguese museums which have attempted to implement an "access for all" approach to the presentation of their permanent collections: Museu Nacional do Azulejo also known as the MNAz (National Tile Museum)); and the Museu da Comunidade Concelhia da Batalha, often referred to as MCCB (Community Museum of Batalha). It will discuss how "access for all" might impact on the cultural value of museum visits for visitors irrespective of their (dis)abilities.

\section{Developing intellectual access: Visitors with visual impairment}

Touch tours, where participants are able to touch selected historic artefacts or works of art in a controlled setting, and 'talking painting' sessions, in which aspects of a painting or artefacts which are not available to touch are described and discussed, are generally reviewed by participants as highly stimulating and satisfying (e.g. Krantz, 2013; Hoyt, 2013). However, although these types of activities for widening participation are interesting, they require forward planning, are cost-intensive, and are often available only to blind people and their companions. Consequently, they do not create equal access. In a survey carried out by the RNIB (Royal National Institute for the Blind, UK) one visually-impaired participant commented "If they [museums] were completely independently accessible from the front door until you are ready to leave, it would mean I could just drop into a museum if I had a free afternoon - go in, by myself, and come out again an hour later, walk home and just be 
able to reflect" (Partington-Sollinger \& Morgan, 2011, p.11). Indeed, Weisen agrees that freedom to visit a museum at any time is crucial: "The possibility of an impromptu visit offers improvisation dream time. It adds hugely to the quality of our lives. It is part of the museum experience." (2011, p.11). Within the population, there is a tiny minority of people with no vision at all, and a small proportion of the population that are legally blind (the majority of which will have some functional vision). Nevertheless, the financial implication to a museum of always having available one or two members of staff who would be able to do a personal guided tour of the building is huge. As such, one of the conflicts with widening participation for people with a visual impairment is the cost/impact ratio.

\section{$\underline{\text { Multisensory information and disability }}$}

In the same way that disability is generally seen as a minority issue, so touch is often used to fill visual gaps created by blindness or low-vision (Candlin, 2006). For example, a 2 1 1 2 D raised line drawing can be used to substitute what is seen by the eyes, in order to provide information about the structural layout of a painting. However, what a touch tour rarely does is to provide the opportunity to explore features that cannot accurately be gauged from vision, such as temperature, weight, solidity and fine texture (Candlin, 2006). Yet, irrespective of visual ability, visitors may want to touch the objects for an intellectual reason, a means of verifying and understanding their true physical nature in a way that sight alone would not allow. Emotional reasons are also important. Museums are still regarded by many visitors as shrines, and so the opportunity to touch a relic can inspire the imagination and give the sense of an intimate encounter with the people historically related to the object (creator, user or owner) that can dissolve the barriers of space and time. Another dimension often ignored is the aesthetic pleasure caused by the experience of touching beautiful objects (Candlin, 2004; Spence \& Gallace, 2008; Reeve, 2006).

The most crucial reason for bringing touch and other sensory modalities out of the 'niche' realm of disability access into the mainstream of the museum experience is, quite simply, that multisensory communication benefits learning. Educators have been advocating the benefits of multisensory training for learning for decades (e.g. Montessori, 2013; Treichler, 1967). Indeed, the advances in brain imaging technologies have enabled researchers to identify some of the brain mechanisms underlying this type of learning. Research has shown that even if people are focusing on information from only one sense, multisensory exposure enhances performance for both perceptual (e.g. Seitz et al., 2006; von Kriegstein \& Giraud, 2006) and memory tasks (Lehman \& Murray, 2005). In both instances, congruency of information in the different senses is important for learning to take place. This is perhaps unsurprising, given the fact that the world within which we operate is a constant source of multisensory stimulation. However, what has surprised researchers is that, although our senses appear to use distinct neural routes into the brain (e.g. eyes for seeing, ears for hearing, hands for touching etc.), our brains are dealing with information in a multisensory way, even in the very early sensespecific processing areas of the brain (e.g. Ghazanfar \& Schroeder, 2006; Driver \& Noesselt, 2008). It is suggested that information delivered in more than sense results in a larger neural network than information encoded in one sense, and it is this that facilitates retrieval (Murray et al., 2005; Nyberg et al., 2000). In other words, the provision of multisensory information could enhance the learning opportunity of all visitors. Evidently, for visually impaired audiences the benefit of multisensory compared to exclusively visual presentation is the difference between nothing and something. Nevertheless, the research suggests that many groups of visitors could benefit from multisensory presentation of information within museums. 


\section{Disability as a minority issue?}

In the context of tight budgets and careful spending in the Museum sector, a counterargument to supporting access initiatives is that it is potentially hard to justify focusing resources on a small population of users. However, the concept of disability as a minority issue is grounded in the way society understands disability. The word disability itself means a lack of ability in one particular area, and implicit in this is the idea that the majority of the population is complete, and the other smaller number is in some way lacking (Barnes \& Mercer 2013). The disability rights movement considered this approach as having a discriminating underlying notion that people with disability were somehow 'other' human beings whose civil rights were denied. This has led to an attempt to reframe disability in the context of human rights, requiring a shift in the definition of 'normal' to 'diverse', so as to include differences in physical, cognitive or sensory characteristics that fall outside of the commonly accepted idea of who is normal (Barnes \& Mercer 2013). Scholars and legislators have conceived a physio-psycho-social model of disability (e.g. ICFDH, WHO 2001), which sees disability as one of the dimensions of human diversity, and diversity is what is 'normal'. Some of them claim that everyone is 'impaired' in one way or another, as everyone has limitations and will experience functional loss throughout life, not only people with a disability (Shakespeare \& Watson, 2001). Beyond disability and impairment, the new approach to access is functional diversity (Patston, 2007).The dis-ability (in the sense of lack of ability) is therefore the result of a disabling society, whose dominant historic and cultural values determine unadjusted responses to these differences, conceiving environments which exclude many individuals (Reich, 2004; Reich et al., 2010).

\section{Museums in Portugal: case studies}

Modern publically-funded museums are coming under ever-increasing scrutiny to demonstrate outcomes and prove that they are offering services to a wide range of the community (Dewdney et al., 2012; Sandell, 2007), whilst continuing to add value to the cultural landscape. Value has often been established in a very reductionist way by simply counting the number of people who enter the museum (Dewdney et al., 2012). Similarly, accessibility is generally addressed as an "aside" to the general museum experience. The two case studies of Portuguese museums have attempted to embrace an inclusive philosophy about museum practice by incorporating multisensory displays into their permanent collections. Both were influenced by the desire to generate a multisensory environment that could provide visitors with the tools to enable them to access the environment in their own way, based on their own interests and abilities. Crucially, both of these case studies were focused not only on physical, but also intellectual "access for all" provisions.

The Museu Nacional do Azulejo [National Tile Museum] (also known as the MNAz) is an important public national museum housed in a historic building, run by the Direção Geral do Património Cultural (DGPC) [General Directorate for Cultural Heritage], who supported the development of an accessibility pilot project for the Ministry of Culture. In contrast, the Museu da Comunidade Concelhia da Batalha (Community Museum of Batalha) (often referred to as MCCB), is a new, small local community museum in Batalha, housed in a newly refurbished building, for which open-access tactile, auditory and visual aids were incorporated into the design and construction. Both of these projects were carried out in the context of the conflicting influences of a heightened awareness and interest in access issues in Portugal and the severe financial crash, which has resulted in a catastrophic cut in funding 
and staff in the arts and culture sector. These case studies demonstrate how different solutions are arrived at by organisations. They also suggest differences in the degree to which accessibility is embraced as a value of the museum.

\section{The National Tile Museum, Lisbon}

The first case study describes a pilot project led by Clara Mineiro in her role at the DGCP, which attempted to make accessible not only the very visual collection the National Tile Museum, in Lisbon (MNAz), but also the historic building in which it was housed. The building which is home to the MNAz is a 16th century convent, refurbished during the 17th and 18th centuries. Within both the original construction and the later refurbishments tiles had been extensively used to decorate the building. In 1959 the building became home to the National Tile Museum, which holds a unique collection of tiles, rescued from demolished convents and palaces from all over Portugal, portraying the evolution of 'azulejos' (tiles), a typical Portuguese craft that dates back to the $11^{\text {th }}$ century and is still present in the 21 st.

The project was designed to create a new open-access provision in the permanent exhibition, allowing independent and impromptu visits which did not need either to be pre-booked or to require a guide from the Education Department of the museum. It was the first Portuguese museum to address the subject of accessibility in such a scale and with such visibility. The multidisciplinary team involved in the project comprised approximately thirty professionals, some working within the Museum and the DGCP, and some external, including Museum professionals, ceramicists, architects, designers, researchers and specialists in the history and conservation of tiles, in accessible communication, or in period music. Every stage of the work was developed in consultation with advisory groups of people with visual and hearing impairment.

The project was designed with three phases. The first involved addressing architectural barriers to access, as this responded to legal imperatives imposed by Portuguese legislation. As part of this process, it was decided which spaces in the old convent should be made accessible and, in each of these spaces, which items in the tile collection should be featured. The second phase concerned the preparation of accessible information about each of the spaces and objects selected. The team wrote extended labels using plain language, in an easyto-read journalistic style approved by the museum curators. The third phase involved the preparation of alternative formats to convey this information, to meet diverse needs in different ways.

One of the most important access tools was the creation of raised tactile reliefs or 'replicas' of selected tile panels. These were integrated within the collection displays. The choice of which tile panels should have tactile reliefs was based on the following criteria: the importance of the original in the collection, the legibility of the image in a tactile form, and the presence of similar tiles or motifs in contemporary daily life of the Portuguese people. For example, a $16^{\text {th }}$ century tile with an armillary sphere was chosen because its motif, a symbol of the Portuguese discoveries, is depicted in the centre of the Portuguese flag (see figures 1 and 2).

Figure 1 about here.

Figure 2 about here. 
The selected originals were reproduced as glazed tiles with raised surfaces. They needed to depict relatively simple designs which could be transformed in $21 / 2$ dimensional representations, easy for visitors to trace with their fingers. More elaborate patterns were broken down in sequences of several individual replicas of the most relevant motifs, alongside one replica combining all the motifs on the same surface (see figures 3 and 4). In some cases, a 3 dimensional representation of one motif or scene in the original tile panel was also provided (see Figures 5 and 6).

Figure 3 about here.

Figure 4 about here.

Figure 5 about here.

Figure 6 about here

In line with the "access for all" philosophy, the replicas were created in white, so as not to compete visually with the originals and to enable partially and fully sighted users to focus on the experience of touch (see figures 6 and 7). Display stands were placed near the originals and were supported by extended labels, in both large print and Braille. The stands were presented at a height suitable for wheelchair users and were designed to contribute to the visual experience, rather than distract from it.

Figure 7 about here.

Figure 8 about here.

The audio guides were intended for use by both sighted, low vision ${ }^{\mathrm{i}}$ and blind visitors. For this reason, the guide was based on audio description. Audio description is defined as: 'aural translation of the visual aspects of a live or filmed performance, exhibition or sporting event for the benefit of low vision and blind people' (Hykes 2005: 6). It was thought that as well as providing crucial information to low vision visitors, it would draw sighted individuals' attention to visual details that would be otherwise ignored. The team was aware that tactile exploration of objects directed by specific audio description is preferable for blind people. However, there was concern that this extra audio description might impair the experience of sighted visitors. Consequently, although the audio guide does not provide a guided exploration of the tactile replicas. However, the audio guides were further enriched with music from different historical periods and illustrative environmental sound effects such as the sound caused by an earthquake, a train approaching the subway station, or strong waves against the rocks. The success of audio guide relies to some degree on the poetic tone used in most of the files, enhanced by the musical choice and the association with contemporary Portuguese cultural values. As an example, the 1701 Lisbon panel is described as a bird's view over the city while the visitor listens to excerpts of the famous fado Gaivota (Seagull) sung by Amália Rodrigues.

Figure 9 about here.

The video guides had two options, sign language or text, and were based around the information on the extended labels within the display. The intention was to provide a 
sensorially enriched experience for all visitors. The project was launched in 3 December 2010.

In order to gather some level of evaluation of the project, a short survey made by the museum covering one hundred users of the multimedia guides in July and August 2011 showed that $99 \%$ of the respondents used the audio guide and $1 \%$ the video guide. In a scale from 1 (bad) to 5 (very good), the audio guides were given an average of 4.78 points. The majority of comments were positive, for example: "The best audio guide I have ever experienced...", “... the clarity and quality of the explanation...", "...the music and the tone of the voices, very instructive...", "... to see time running for each point...". But there were some criticisms "The contents were sometimes a bit too long" or "Sometimes they say too much or describe what I already see". It is worth noting that users were not made aware of the inclusive nature of the guides.

Further evaluation comes from the visitor's comment book, where visitors comment on aspects of their visit. While not representative data, there are some positive comments that specifically refer to the access provision, but the majority did not mention access accommodation. The comment below supports the informal view of the Education department that the provision is having a positive impact on visitors:

"Thank you for providing a wonderful experience for the visually impaired - as well as those not. The audio and tactile exhibits are easy to use and made our visit thoroughly enjoyable. Thank you! JC and LC, Colorado USA."

The data on visitor use suggests that the provision has had a positive impact on visitor experience. However, these positive experiences have not been matched by a substantial rise in visitors with special needs, as evidenced by the ticketing system which provides information on the number of visitors with special needs based on the reduction of the admission fee for visitors who identify themselves as disabled (see Table 1). Numbers did increase significantly in 2011, the year after the project was launched. There was a $580 \%$ increase in Portuguese visitors with a disability. However, although overall numbers of visitors to the museum have increased year on year, the number of visitors with disabilities declined in 2012 and 2013, particularly amongst Portuguese visitors. There was a small increase in 2014, but not close to the levels of visitors following the opening of the provision in 2011.

Table 1 about here.

One possible explanation for this is that due to the severe financial cuts in museum funding publicity for the access provision has been very poor; there are no outreach initiatives and no inclusive temporary exhibitions or programmes. Consequently, the level of visitors with a visual or hearing impairment is still disappointingly low. Seemingly, word of mouth is not sufficient to maintain public awareness or interest and publicity is crucial.

It was worth noting that the MNAz was selected for the pilot project of the Ministry of Culture based on outreach work that the museum was doing at the time. However, the project was not incorporated by the Museum into an ongoing strategic access plan, in which all departments and members of staff had a role to play in assuring the direction and success of the project. As a consequence, "access for all" has not been taken on as a core value within 
the practice of the museum curatorship. One might suggest that this is a result of the financial crash, in which organisations have had to struggle to maintain basic levels of provision, and projects such as this, which challenge traditional museological practices, have been deprioritised. So whilst feedback suggests that open-access provision is well received by the public, such projects need to be embraced within the museum's curatorial priorities and ethos. Without that, accessibility will remain a minority issue at the margins of mainstream activities and programmes, even when it is given priority status through political action.

The MNAz project had considerable impact in the media, mainly newspapers and television. However, the reaction to this approach in the Portuguese museum context was subtle, though positive. Several museum professionals left encouraging comments in the visitors' book and the Portuguese Museum Network organized several workshops to disseminate and discuss this access project, but there was poor response in terms of inspiration for experiences in other museums. Aragall, Neumann \& Sagramola (2008) argue that 7 (seven) Interdependent Success Factors (ISF) are necessary to grant the success of an access project in a built environment: (1) decision-maker commitment; (2) coordinating and continuity; (3) networking and participation; (4) strategic planning; (5) knowledge management; (6) resources; (7) communicating and marketing. According to Aragall et al., (2008), the simultaneous presence of all the 7 ISF in the same project greatly enhances the possibility of success. For the MNAz most of these factors were present during the period of preparation and launching of the project. On the other hand, Walter's research (2008 and 2009) shows "that despite anti-discrimination legislation and efforts by museums to improve access, the issue of attitude [of museum professionals] remains a key barrier to genuine inclusion for deaf and disabled people" (Walters, 2008, p.1). For this project, although the ground work was in place for long-term success, ultimately there was not sufficient ongoing commitment to sustain and develop the initial successes.

Although other concerns are prioritised over access at the MNAz or at any of the public museums under the umbrella of the DGPC, it has become an important concern at the monuments run by Parques de Sintra - Monte da Lua (PSML). This is a state-owned company with a private management which is responsible for the natural and cultural landscape of Sintra and Queluz (near Lisbon), which has made good physical and intellectual access for a wide range of visitors part of the management model ${ }^{1}$. This has, in turn, brought them awards at both national and international level.

This project has had an impact on thinking and practice in Portugal, The project has opened doors for the DGPC for the development of ongoing major research projects - the internal Access Audit to all Heritage sites dependent on this institution (41, in total) and the Communication and Inclusive Project for the World Heritage sites in the central region of the country, which will hopefully be funded soon by the European Community Programme Portugal 2020.

\section{$\underline{\text { The Community Museum of Batalha }}$}

The second case study provides an example of "access for all" working at the centre of the museological approach from the inception of the museum plan. The MCCB is a small local by the Town Council of Batalha (the Portuguese word for

https://www.parquesdesintra.pt/en/about-us/management-information/management-model/ 
'battle'), named after the Battle of Aljubarrota. The battle, fought nearby in 1385 between the King of Portugal and the Kingdom of Castela, granted Portugal its independence from Spain and led to the construction of a monastery in commemoration of the victory from which the present town originated. The town is proud of its unique origins and the Local Council set up its local museum which opened to the public in April 2011. The museum's collection is essentially composed of archaeological and ethnographic items which document the history of the town and region, mainly on loan from members of the local population.

The decision to make the small museum a "museum for all", demonstrates social awareness but also indicates how accessibility projects can be politically strategic. Access was already positioned as a central tenet of the Local Council, but it also represented a means for differentiation. Rather than considering access as a minority issue, the MCCB addressed it as integral to the concept of the museum - an unobtrusive statement that everybody, regardless of their (dis)ability, could share. Given its small size and the fact that it is built in the shadow of the world heritage Monastery of Batalha, the MCCB and the story of the small town would have gone unnoticed had it not been given characteristics that made it different from other museums in the country. As such, "access for all" was highlighted as part of the unique 'cultural value' of a visit to this museum. Both the importance and the success of this approach, have been recognised nationally by the Portuguese ICOM 2012 award and Acesso Cultura 2014, and internationally by the prestigious Kenneth Hudson (EMYA) 2013 award.

The concept of accessibility was applied at all levels. A core concept of the museum was that it would tell multiple stories, through different voices whilst at the same time devising opportunities for visitors to feed in their own "voice" while visiting (achieved through participatory workshops and visits, in which the locals are invited as guides and young and old are invited to reinterpret the "stories" the museum tells). The goal was that local people who visited the MCCB would recognise their cultural wealth and their personal stories as worthy of display and communication, and that national visitors, foreign to the region, would be given the opportunity to understand the unique and shared aspects of local culture within the nation's history. However, translating local culture to international visitors could be difficult because some of the basic concepts would be alien to them, so the aim of making 'otherness' comprehensible became incorporated in the museum's approach to accessibility. Thus, MCCB was developed in a way which would maximise access to information enabling all visitors to find their personal journey through the museum.

MCCB used a team of experts, led by Dr Joselia Neves, from different scientific and technical backgrounds and with different skills who worked together as a coherent whole production team. An advisory committee was also established representing the interests of blind people and people from other disability groups. Getting the whole team to understand the importance and the basics of an accessible museum, and to be committed to it, was one of the most important issues of this project and required a joint effort on behalf of each member and a strong political commitment and sense of direction. The fact that the Batalha Local Council had made accessibility a priority made a significant difference and kept the whole group focused on finding solutions that would satisfy the level of quality that the project had set for itself.

The approach to architecture, design and layout was one of simplicity, clarity and spatial awareness, seeing the museum as a "text" to be read and understood at all levels. Details such as the choice of materials, lighting, layout, positioning were constantly evaluated on the level of what they could add to communicating the narratives of the museum, supporting access for 
the broadest audience. Accessibility was considered both in terms of physical access within the environment, and access to the content of the museum.

The majority of accessibility considerations, both physical and intellectual, were simply incorporated throughout the museum exhibition to be used by all. For example, a visual/tactile floor plan greeted people at the entrance (see figure 10). Touchable objects were incorporated into the permanent collection within cabinets and showcases were designed to be accessible to everyone; audio description, including guided touch, was incorporated in the standard audio guide. The MCCB shared its approach to that presented at the MNAZ by using the same technology and presenting content in a similar way. Beyond the informative layer that audio guides usually present, the audio guide in Batalha interwove description and the voices of local people with the more general information offered by the narrator. Going beyond the guides at MNAZ, at the MCCB, in the stops on the audio tour that allowed for touch, it guided the visitors' hands in the exploration of real objects, replicas or raised pictures. An additional layer was added to contribute towards blind people's autonomy, by guiding their movement in space and allowing them to move freely throughout the whole exhibition space.

Figure 10 about here.

In addition, all printed text was made available in Braille (see figure 11). Information presented in digital formats, such as virtual books on interactive displays, were also made available in analogue formats (i.e. paper), videos were subtitled, and colourful pictures and small print texts were also made available in black and white, high contrast and big print. Some of these measures only met the needs of a specific disabled group; for example, object labels and museum texts were made accessible for blind people in the form of Braille in various places; for hearing impaired visitors, video guides in sign language were provided. However, the majority of solutions were common to all visitors.

Figure 11 about here

Disputes regularly arose between the different viewpoints. For example, architecture, exhibits and communication strategies often appear to have quite different needs. However, with accessibility as a unifying goal, each design or curatorial proposition was confronted with the question "how will $x$ affect access?". This question was often broken up into multiples by specifying the profiles of the envisaged visitors and the list expanded to "how will $\mathrm{x}$ affect access to people with poor eye sight, to people with hearing impairment, to children, to foreigners?". However, discussions also needed to take on multiple concerns and concepts such as preservation, safety, hardiness, and fidelity to history and the purpose behind the exhibits themselves. Finding solutions that would guarantee access and yet not jeopardise the interests of museology at large were equally central. Consequently, the museum's initial quest for perfection took on a more humble stance of "the possible" as compromise became an important aspect of the project. Success was always measured in the light of the possible, rather than of that of the ideal. Only when the answers became satisfactory to the greatest number of profiles possible did the team move on to the next issue.

Two examples demonstrate how such compromises were reached. The first shows an instance where the solution to a problem led to a better experience for visitors than would have been achieved by the originally proposal. The second illustrates that an " access for all" provision can also create issues that cannot easily be resolved by the creation of a single unified 
resource. Rather it responds to needs with different solutions that operate through different forms.

The first example is of a 3D model of the Monastery, designed to show the different phases in which the Monastery was built and the four distinctive components that form it. The original concept was that there would be a video shown on a screen which would show a 3D virtual reconstruction of the architectural changes in the Monastery. This would be supported by three 3D printed tactile models showing how each of the "new" phases contributed to the architectural whole. The models were made using additive technology, faithful to scale and detail, and were beautiful clean white pieces that were intended to be appealing to the eye and touch.

Initial tests by blind people on the advisory committee soon made it clear that these faithful replicas were far too detailed and on too small a scale to be informative (see figure 12). The first step taken in response to this was to provide the advisors with tactile replicas of the Monastery's gargoyles (see figure 13). The size, texture and, above all, their simplicity resulted in the gargoyles being identified as one of the highlights of the museum by the advisory panel.

Figure 12 about here

Figure 13 about here

Figure 14 about here

Figure 15 about here

Following on from this, a "less is more" approach was taken to the representation of the Monastery. A simple plywood "puzzle model" was cut out and sprayed in bright highly contrasting colours (see figure 14). Each piece represented part of the Monastery and was made to fit in neatly on a tray. Observation of visitors and feedback indicates that it is used by a broad range of visitors including teachers, children, people with visual impairment, architects and other members of the general public. The model is sturdy, playful and tactually appealing. It contributes to a multisensory experience and complements the other elements of the display dealing with the monastery, including the audio guides with a detailed description; 3D virtual model video; printed and braille materials; other replicas and models of specific parts of the monastery (see figure 15).

In the second example, a 'territory map' was planned as a 2 metre wide interactive table-top model with a relief map of the territory of Batalha. This scaled model was to be an interactive device that revealed information on the routes to Batalha's natural resources, cultural heritage, points of interest, walking or biking tracks, among others. These routes were to be projected on the relief model, with more detailed information concurrently presented on a screen placed on the side, while photographs of the region were shown on a screen on the facing wall. This was conceptualised as an important asset in the MCCB because it would entice visitors to go out and experience the countryside themselves.

In theory, the multimedia territory map had all the components necessary to be a highly effective and accessible feature in the museum. It would appeal to a number of different senses: the raised map could be touched for a sense of the territory's relief, the photos were 
visually appealing and informative to visitors with a sense of sight, and the information about the region could be accessed in a visual or aural form. However, while it was still in the construction phase unforeseen issues relating to the scale of the piece and its positioning made it impossible to develop as a touching interactive model. The furniture itself was amended to allow for easier use by people in wheelchairs (see figure 16), but concerns over maintenance and hardiness made it clear that the model would be damaged if people were to be allowed to touch it without constraint. Consequently, the relief was cased in order to preserve it. What had been envisaged as a multisensory device had become a primarily visual experience.

Figure 16 about here

Figure 17 about here

The compromise was to create an interactive table with written and visual information for sighted individuals that was also made available on a computer with a screen reader, allowing blind people to access the information. The information was also available in analogue, print and braille versions. The compromise solution did not provide blind visitors with the multimodal experience they would have had under the original design but, in terms of content and provision for learning, they were given an equivalent experience to other visitors (see figure 17).

Where problems arose, the museum team had to take on the development of accessible solutions as a learning opportunity. Finding solutions stimulated creativity and helped the team to understand how people 'live' the museum. As a result, the MCCB sees itself as an organic laboratory, where further tests and studies are carried out and where strategies are devised, tested, and the presentation of information is changed or improved. This cycling continuum characterises this as an action research project and acknowledges that "access for all" requires an ongoing process of trial and error and constant improvement.

It has since become a reference at national and international levels and is now seen as an example for others to follow. Museum curators, researchers of inclusive communication and design, and people interested in access in museums and in wider contexts from all over the world have visited the MCCB and taken home with them notions that have since been implemented in their museums. Examples of this are: the new Museu da Universidade de Pelotas in Brazil, which has been modelled on the MCCB; or MA and PhD research works that have taken it as their case study, or even the many people who have come to this small museum for their internship. All are reasons to believe that the MCCB now plays an important educational role in the wider context of museum and communication studies and practices.

\section{Next Steps with Access for All}

Both of these "access for all" case studies grew out of the deep financial crisis in Portugal. For the National Tile museum, obliteration of public funding meant that traditional staffintensive routes of access for blind individuals - touch tours and visual painting sessions were financially prohibitive. Likewise, from a practical perspective, the very small, local community museum was going to struggle to provide individual access provision for low vision individuals. However, the solution of both projects was more than simply a way to provide access to the disabled minority. Underlying both was a vision of access as a shared, 
common museum experience. The importance of this endeavour should not be underestimated. Traditionally, disability in museums and in galleries is seen as a separate issue. It is dealt with alongside mainstream provision. Access provision may be interesting to users, and in some instances it can provide users with experiences that are prohibited to 'normal' visitors (for example, permission can be given to touch an object or statue on a touch tour which is not possible for other visitors). However, these experiences are very much on the periphery of the museum experience and are certainly not the starting point for design (as was the case for the MCCB).

The shared experience, underpinned by an understanding of multisensory processing develops the important Universal Design for Learning (UDL) approach to museum design described by Rappolt-Schlichtmann and Daley (2013) by emphasising the benefits to all museum visitors. The ethos underlying both case studies is enhanced experience and inclusivity for all visitors. Whether visitors are aware of this or not, it is providing examples to the visitor of ways and means through which we can find our commonality. Whilst the intention was present in both case studies, the National Tile Museum struggled to embrace this fully. The primary aim was to create a shared enriched experience. Sighted people not normally able to experience the feel of the tiles, could enhance their visual experience with the textures and patterns. Participants without sight could experience descriptions of the form in words and at the same time feel those shapes. However, the vision of commonality was being applied to an already existing display, and concerns about compromising the 'sighted' experiences resulted in compromises to the disabled visitor's experience (for example, by not including guided touch in the audio descriptions). Further, the National Tile Museum itself had difficulty embracing the concept of inclusivity moving forward and whilst the numbers of visitors are rising year on year, the numbers of disabled visitors are falling.

The processes the MCCB team went through in the development stages demonstrate that the common goal of "access for all" needs to be strongly dictated from the highest levels. The visionary stance on access of Batalha's Local Council, combined with the focused effort of the MCCB team, has created something truly outstanding, as recognised by the receipt of the Kenneth Hudson award. This museum is, in reality, a local, small town museum. But the experience it creates adds something of value not only to the cultural landscape, but also to society as a whole. It demonstrates that we can share our world, without impairing anyone's experiences. All this is achieved with the integrity of the museum intact.

If these museums were both attempting to redefine (dis)ability by producing an experience that could be shared and experienced in a way defined by each individual visitor, by providing information through multisensory means, they are potentially also improving the long term memory or impact of the museum visit for all visitors. Multisensory information not only plays a significant role in learning semantic information or 'facts', it also plays a significant role in our autobiographical memories. Autobiographical memory is memory for information related to the self (Brewer, 1986) and it is generally agreed that we recall these memories by reconstructing them from of pool of sensory traces in the full wealth of modalities (Eardley \& Pring, 2006). While the visitor to the museum may talk about wanting an experience, arguably the end product that the visitor is seeking is an autobiographical memory - a memory which feeds in to and enriches their notion of self. Furthermore researchers have already identified the importance of long-term memory as a means of evaluating a museum visit (e.g. Anderson, 2003; Anderson \& Shimizu, 2007; Falk \& Dierking, 1997; Falk \& Dierking, 2012). 
Some museums could argue that "access for all" is not an appropriate approach for their institutions. The inclusion of tactile displays would significantly change the traditional layout of most art galleries. However, if multisensory information enhances semantic and autobiographical memory, then multisensory presentation of information should not be a minority issue aimed at providing access for a few visitors; rather it should be at the centre of a museum experience, enabling understanding for all visitors. Within the climate of the 'experience economy' (Kelly, 2004), where museums and other cultural sites are in direct competition with many other leisure activities and companies, all of whom have to offer experiences that sell (Pine \& Gilmore, 1998), arguably what the museum curator strives to provide and the museum visitor strives to achieve is a memorable visit, with emotional resonance (e.g. Del Chiappa et al., 2014). Whether it be through increased semantic knowledge, or a self-defining experience, memorability is an integral factor in long-term impact (McManus, 1993). The multisensory Portuguese museum displays are typical in that they have not been evaluated in a form that allows the museum to understand how they affect memorability. What is clear is that deeper and more consistent research into the impact of inclusivity and multisensory displays on both all (dis)abled visitors is needed.

\section{REFERENCES}

Anderson, D. 2003. Visitors' Long $\square$ term Memories of World Expositions. Curator: The Museum Journal, 46(4), 401-420.

Anderson, D., \& Shimizu, H. 2007. Recollections of Expo 70: Visitors' Experiences and the Retention of Vivid Long $\square$ Term Memories. Curator: The museum journal, 50(4), 435-454.

Aragall, Neumann \& Sagramola (2008). ECA [European Concept for Accessibility] for Administrations. EuCAN: Luxemboug.

Assembly, UN General. Universal declaration of human rights. Resolution adopted by the General Assembly 10, no. 12 (1948).

Barnes, C. and Mercer, G. 2010. Exploring Disability, 2nd Edition, Cambridge: Polity

Brewer, W F. 1986. What is autobiographical memory? in Rubin, David C. (Ed). Autobiographical memory. , pp. 25-49. New York, NY, US: Cambridge University Press

Candlin, F. 2004. Don't touch! Hands off! Art, blindness and the conservation of expertise. Body \& Society 10, no. 1, 71-90.

Candlin, F. 2006. The dubious inheritance of touch: Art history and museum access. Journal of Visual Culture 5, no. 2, 137-154.

Candlin, F. 2009. Art, museums and touch. Manchester University Press.

Chatterjee, H J. 2008. Touch in museums: Policy and practice in object handling. Oxford: Berg. 
Chatterjee, H. J. and Noble, G. 2013. Museums, Health and Wellbeing. Farnham: Ashgate Publishing Ltd.

Classen, C. 2005. (ed). The book of touch. Oxford: Berg.

Del Chiappa, G, Andreu,L. and Gallarza, M. G. 2014. Emotions and visitors' satisfaction at a museum. International Journal of Culture, Tourism and Hospitality Research 8, no. 4, 420431.

Dewdney, A., Dibosa,D., and Walsh, V. 2013. Post critical museology: theory and practice in the art museum. Routledge

Driver, J., and Noesselt, T. 2008. Multisensory interplay reveals crossmodal influences on 'sensory-specific'brain regions, neural responses, and judgments. Neuron 57, no. 1, 11-23.

Eardley, A. F., and Pring, L. 2006. Remembering the past and imagining the future: A role for nonvisual imagery in the everyday cognition of blind and sighted people. Memory 14, no. $8,925-936$.

European Commission (EC). (2010). European Disability Strategy 2010-20. Retrieved September 4, 2012, from http://eurlex.europa.eu/LexUriServ/LexUriServ.do?uri=COM:2010:0636:FIN:EN:PDF

European Commission (EC). (2014). Economic impact and travel patterns of accessible tourism in Europe - final report. Retrieved February 11th, 2015 from: file:///C:/Users/eardlea/Downloads/study\%20A\%20Economic\%20Impact\%20and\%20travel $\% 20$ patterns\%20of\%20accessible\%20tourism_final.pdf

Falk, J. H., \& Dierking, L. D. 1997. School field trips: assessing their long $\square$ term impact. Curator: The Museum Journal, 40(3), 211-218.

Falk, J. H., \& Dierking, L. D. 2012. Museum Experience Revisited. Left Coast Press.

Gallace, A., and Spence, C. 2010. The science of interpersonal touch: an overview. Neuroscience \& Biobehavioral Reviews 34, no. 2, 246-259.

Ghazanfar, A. A., and Schroeder, C. E. 2006. Is neocortex essentially multisensory?. Trends in cognitive sciences 10 , no. 6, 278-285.

Ginley, B. 2013. Museums: A Whole New World for Visually Impaired People. Disability Studies Quarterly 33, no. 3

Hirose, K. 2013. Research on Methods of "Touching the World"-The Aim of the Exhibit Area of Tactile Learning in Japan's National Museum of Ethnology. Disability Studies Quarterly 33, no. 3.

Hoyt, B O. 2013. Emphasizing Observation in a Gallery Program for Blind and Low-Vision Visitors: Art Beyond Sight at the Museum of Fine Arts, Houston. Disability Studies Quarterly 33, no. 3. 
Hyks, Veronika (2005): 'Audio Description and Translation: Two Related but Different Skills', Translating Today, 4 (July), 6-8.

Kelly, L. 2004. Evaluation, research and communities of practice: Program evaluation in museums. Archival Science 4, no. 1-2, 45-69.

Krantz, G. 2013. Leveling the Participatory Field: the Mind's Eye Program at the Guggenheim Museum. Disability Studies Quarterly 33, no. 3

Lehmann, S., and Murray, M. M. 2005. The role of multisensory memories in unisensory object discrimination. Cognitive Brain Research 24, no. 2, 326-334.

McManus, P. M. 1993. Memories as indicators of the impact of museum visits. Museum management and curatorship 12, no. 4, 367-380.

Montessori, M. 2013. The montessori method. Transaction Publishers,

Murray, M. M., Molholm, S., Michel, C. M., Heslenfeld, D. J., Ritter, W., Javitt, D. C., Schroeder, C. E., and Foxe, J. J. 2005. Grabbing your ear: rapid auditory-somatosensory multisensory interactions in low-level sensory cortices are not constrained by stimulus alignment. Cerebral Cortex 15, no. 7; 963-974.

Nyberg, L., Habib, R., McIntosh, A. R., and Tulving, E. 2000. Reactivation of encodingrelated brain activity during memory retrieval. Proceedings of the National Academy of Sciences 97, no. 20; 11120-11124.

Patston, P. 2007. Constructive Functional Diversity: A new paradigm beyond disability and impairment. Disability \& Rehabilitation 29, no. 20-21, 1625-1633.

Partington-Sollinger, Z., and Morgan, A. 2011. Shifting Perspectives Opening up museums and galleries to blind and partially sighted people CultureLink. London: RNIB

Pine, B. J., and Gilmore, J. H. 1998. Welcome to the experience economy. Harvard business review 76, 97-105.

Rappolt $\square$ Schlichtmann, G., \& Daley, S. G. 2013. Providing access to engagement in learning: The potential of Universal Design for Learning in museum design. Curator: The Museum Journal, 56(3), 307-321.

Reich, C. 2004. Museums, accessibility and evaluation." Visitor Studies Today 7, no. 3, 1-3.

Reich, C., Price, J., Rubin, E., and Steiner, M. A. 2010. Inclusion, Disabilities, and Informal Science Learning. A CAISE Inquiry Group Report. Center for Advancement of Informal Science Education

Reeve, J. 2006. Prioritizing Audience Groups. In Lang, C., Reeve, J., \& Woollard, V. (eds). The Responsive Museum: Working with Audiences in the Twenty-First Century. Ashgate Publishing, Ltd. 
Sandell, R. 2007. Museums, Prejudice and the Reframing of Difference, Routledge: London and New York

Seitz, A. R., Kim, R., and Shams, L. 2006. Sound facilitates visual learning. Current Biology 16, no. 14, 1422-1427.

Shakespeare, T., and Watson, N. 2001. The social model of disability: an outdated ideology? In: Exploring Theories and Expanding Methodologies: Where We Are and Where We Need to Go. Series: Research in social science and disability (2). JAI: Amsterdam and New York, pp. 9-28

Treichler, D. G. 1967. Are you missing the boat in training aids. Film and audio-visual communication 1, 14-16.

Von Kriegstein, K., and Giraud, A-L. 2006. Implicit multisensory associations influence voice recognition. PLoS biology 4, no. 10, e326.

Walters, D. (2008). Attracting zealots. Responses to disability in contemporary museums in the early $21^{\text {st }}$ century (PhD Thesis). Newcastle University, Newcastle.

Walters, D. (2009). Approaches in museums towards disability in the United Kingdom and the United States. Museum Management and Curatorship, 24(1), 29-46.

Weisen, M. 2011. Preface in: Partington-Sollinger, Z., and Morgan, A. 2011. Shifting Perspectives Opening up museums and galleries to blind and partially sighted people CultureLink. London: RNIB 


\section{Figures}

Figure 1: MNAz - Armillary sphere - original. (credit: Clara Mineiro)

Figure 2: MNAz - Armillary sphere - replica. (credit: Clara Mineiro)

Figure 3: MNAz - Grasshoppers: Display stand near the original. (credit: Clara Mineiro)

Figure 4: MNAz - Grasshoppers: Replica with pattern broken in individual motives. (credit: Clara Mineiro)

Figure 5: MNAz - The dance lesson: Replica with a 3 dimensional representation of the scene. (credit: Clara Mineiro)

Figure 6: MNAz - The dance lesson - original (credit: Clara Minero)

Figure 7: MNAz - Camelias: Display stand near the original. (credit: Clara Mineiro)

Figure 8: MNAz - Camelias: Visually impaired member of the advisory group testing the audio guide. (credit: Clara Mineiro)

Figure 9: MNAz - Lisbon panorama - original. (credit: Clara Mineiro)

Figure 10: MCCB - Museum floor plan (credit: Joselia Neves)

Figure 11: MCCB - Replica of D. Manuel Weights and Measurement (credit: Joselia Neves)

Figure 12: MCCB - Testing the 3D model of the Monestary. (credit: Joselia Neves)

Figure 13: MCCB - The Gargoyle model detail on the Monestary. (credit: Joselia Neves)

Figure 14: MCCB - The basic puzzle model of the Monestary. (credit: Joselia Neves)

Figure 15: MCCB - The current set up: visitors using the puzzle. (credit: Joselia Neves)

Figure 16: MCCB - Testing the height of the table. (credit: Joselia Neves)

Figure 17: MCCB - Using the finished table and display. (credit: Joselia Neves)

\footnotetext{
' Low vision is a condition when visual acuity is $20 / 70$ or poorer and cannot be corrected or improved with regular eyeglasses.
} 